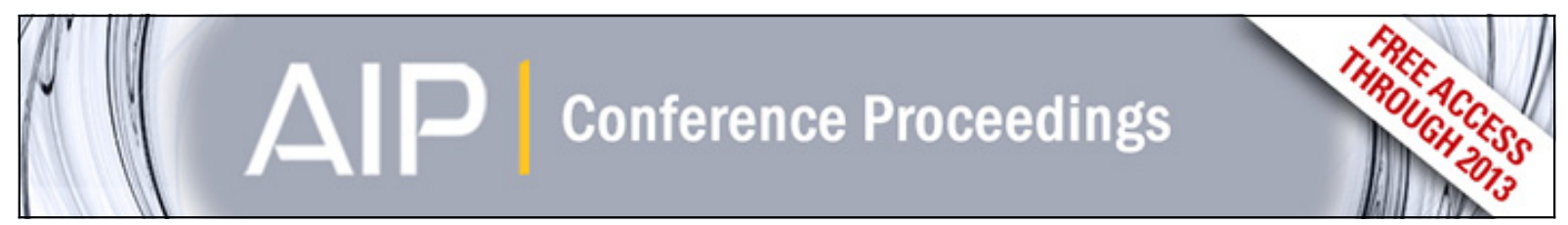

Temperature-dependant study of phosphorus ion implantation in germanium

M. A. Razali, A. J. Smith, C. Jeynes, and R. M. Gwilliam

Citation: AIP Conference Proceedings 1496, 193 (2012); doi: 10.1063/1.4766522

View online: http://dx.doi.org/10.1063/1.4766522

View Table of Contents: http://scitation.aip.org/content/aip/proceeding/aipcp/1496?ver=pdfcov

Published by the AIP Publishing 


\title{
Temperature-Dependant Study Of Phosphorus Ion Implantation In Germanium
}

\author{
M.A. Razali, A.J. Smith, C. Jeynes, and R.M. Gwilliam \\ Surrey Ion Beam Centre, Advanced Technology Institute, Faculty of Engineering and Physical Sciences, University \\ of Surrey, Guildford, Surrey, GU2 7XH, UK
}

\begin{abstract}
We present experimental results on shallow junction formation in germanium by phosphorus ion implantation and standard rapid thermal processing. An attempt is made to improve phosphorus activation by implanting phosphorus at high and low temperature. The focus is on studying the germanium damage and phosphorus activation as a function of implant temperature. Rutherford backscattering spectrometry with channelling and Hall Effect measurements are employed for characterisation of germanium damage and phosphorus activation, respectively. High and low temperature implants were found to be better compared to room temperature implant.
\end{abstract}

Keywords: Phosphorus, Ion Implantation, Damage, Germanium, High and low temperature implantation.

PACS: 61.72.U-; 73.61.-r

\section{INTRODUCTION}

Germanium has received much attention in recent years due to its high carrier mobility and has the further advantage of being compatible with silicon processing technologies. To use germanium as the replacement for the transistor channel, a process for high activation and low diffusion for both $\mathrm{p}^{+}$and $\mathrm{n}^{+}$ doping is required.

Previous investigations [1] have shown that p-type (mostly boron) shallow junction implemented in germanium exhibit high activation and well-behaved junction characteristics, satisfying the ITRS [2] demand for the $22 \mathrm{~nm}$ technology mode. However, ntype shallow junctions formed using phosphorus as the dopant species do not yet satisfy these requirements due to a high diffusivity and low levels of electrical activation [3].

Although the effects of co-implantation [4], irradiation [5] and laser annealing [6] have been investigated previously, little attention has been paid to the effect of implant temperature on phosphorus diffusion and activation. The goal of this study is to present results on the amorphisation and activation behaviour of phosphorus, implanted at various implant temperatures and annealed isothermally and isochronally annealing using rapid thermal processing (RTP).

\section{EXPERIMENTAL}

P-type (100) germanium on silicon (Ge-on-Si) wafers, grown at University of Warwick, UK, with starting resistivity of about $16 \mathrm{ohm}-\mathrm{cm}$ were used in this study. Prior to implantation, the samples were capped with $10 \mathrm{~nm}$ silicon nitride, deposited using the PECVD process at a temperature of $300^{\circ} \mathrm{C}$. The wafers were subjected to phosphorus ion implantation at $30 \mathrm{keV}$ with a dose of $1.125 \times 10^{15} \mathrm{~cm}^{-2}$ at room temperature (RT), liquid nitrogen temperature $\left(\mathrm{LN}_{2}\right)$ $\sim 77 \mathrm{~K}$ and at a temperature of $500^{\circ} \mathrm{C}$. In order to minimise channelling, the implantations were performed under $7^{\circ}$ tilt angles.

Rutherford Backscattering Spectrometry channeled in the (100) direction (RBS-c) measurements were used to monitor the germanium damage .The amorphous depth was measured using a $1.1 \mathrm{MeV}^{4} \mathrm{He}^{+}$ beam at a glancing angle of $45^{\circ}$ to the sample, and the resulting spectra were analysed using the IBA DataFurnace software developed at the University of Surrey [7]

RTP steps were done using a Jipelec Jetstar 200ST, in a 60 s isochronal scheme from $500^{\circ} \mathrm{C}$ to $800^{\circ} \mathrm{C}$ and a $800^{\circ} \mathrm{C}$ isothermal scheme from $10 \mathrm{~s}$ to $120 \mathrm{~s}$. The cap layer was stripped using buffered HF solution before characterisation. Hall measurements were performed using an Accent HL5500 on $1 \mathrm{~cm}^{2}$ samples using the Van der Pauw (VDP) geometry to extract the number of carriers (Ns), corresponding sheet resistance (Rs) and their mobility $(\mu)$. The VDP structures were created using standard photolithography and wet chemical etching. 


\section{RESULTS AND DISCUSSION}

\section{Characterisation Of Germanium Damage}

Figure 1 shows the ion channelling spectra for samples implanted at $\mathrm{RT}, \mathrm{LN}_{2} \& 500^{\circ} \mathrm{C}$ along with a virgin sample for comparison. A selected portion of the RBS-c spectra (channel 240 to 285) was chosen to show and emphasize the germanium damage peak.

The implantation damage is clearly visible in the samples implanted at $\mathrm{LN}_{2} \& \mathrm{RT}$ as the dechannelling yield for both samples, which have similar trend, are far higher than the virgin sample. An equivalent amorphous germanium (a-Ge) layer thickness of $52.3 \mathrm{~nm}$ and $63 \mathrm{~nm}$ are formed for RT and $\mathrm{LN}_{2}$ implants, respectively. The sample implanted at $500^{\circ} \mathrm{C}$ shows very little dechannelling yield indicating marginal residual damage following the implantation. As expected, the channelling spectra indicate that with increasing implantation temperature, the degree of germanium amorphisation is reduced.

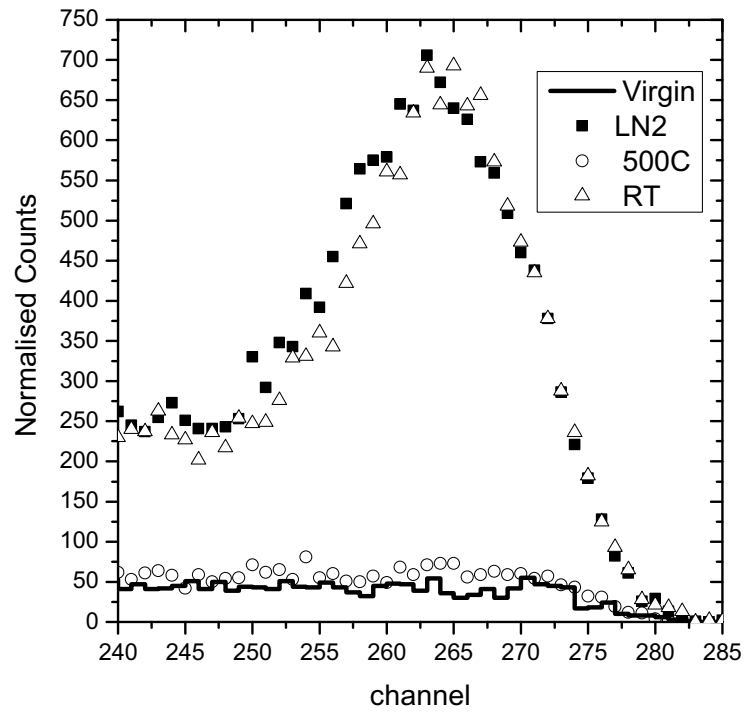

FIGURE 1. This RBS spectra of a virgin (line) germanium structure in comparison to corresponding channelling spectra after $30 \mathrm{keV}, 1.125 \times 10^{15} \mathrm{~cm}^{-2}$ phosphorus implantation at $\mathrm{RT}$ ( triangle), $\mathrm{LN}_{2}$ (square) \& $500^{\circ} \mathrm{C}$ (circle), respectively.

During implantation at $\mathrm{LN}_{2}$, the dynamic annealing is basically not present. Therefore, the damage is agglomerated to form a continuous amorphous layer. However, the implantation at RT results in a narrower amorphous region than the $\mathrm{LN}_{2}$ implant due to some recombination process that occurs during the implantation process. In the case of the phosphorus implantation at high temperature, most of the associated displacement damage will recover by the mutual recombination of self-interstitial atom and vacancies.

\section{Phosphorus Electrical Activation}

The electrical results after isochronal annealing studies are shown in figures 2 through 4 . Figure 2 shows sheet resistance (Rs) as a function of implant temperature. Figure 3 shows sheet carrier concentration (Ns) over the same implant temperature range and Figure 4, the Hall mobility. The trends in Rs, Ns and mobility for RT implant in Figure 2, 3 and 4 , closely resemble the results obtained by Poon et al. [8].

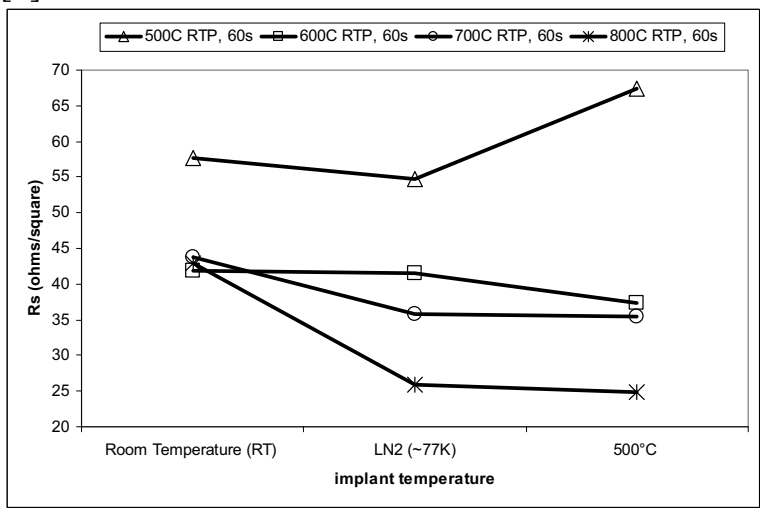

FIGURE 2. Sheet resistance after $500,600,700$ and $800^{\circ} \mathrm{C}$ annealing for different phosphorus implantation temperatures.

For samples implanted at $\mathrm{LN}_{2} \& 500^{\circ} \mathrm{C}$, the sheet resistance decreases as the anneal temperature increases (Fig 2). This is essentially due to the increase in the sheet carrier concentration (Fig. 3). However, as the RTP temperature is increased from 600 to $800^{\circ} \mathrm{C}$, the sheet resistance for RT implant samples, saturate with increasing temperature (Fig 2). The saturation in sheet resistance is coincidental with the decrease of sheet carrier concentration as observed in Fig. 3.

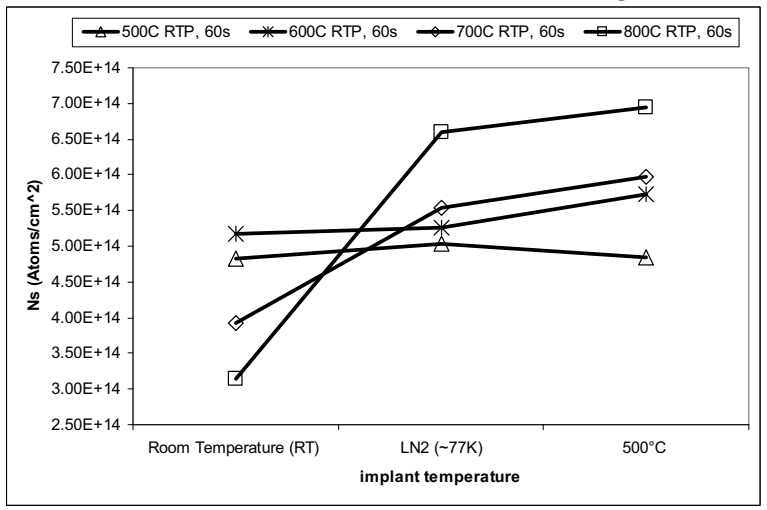

FIGURE 3. Sheet carrier concentration after 500, 600, 700 and $800^{\circ} \mathrm{C}$ annealing for different phosphorus implantation temperatures.

As shown here and suggested by Simoen et al. [9], very low levels of damage remain following implantation at $500^{\circ} \mathrm{C}$. From this low damage level 
starting point, good activation of phosphorus is achieved due to the low level of stable defect complexes.

At $\mathrm{LN}_{2}$ temperature, where no dynamic annealing is present, Frenkel pairs remain within close proximity to one another and annihilate easily during annealing. This again leads to a situation of low levels of complex thermally stable defects and hence, good activation.

However, for the RT implant case, due to the dynamic annealing, more complex defect structures form resulting in the thermally stable defects, which are thought to bind the phosphorus in an electrically inactive state.

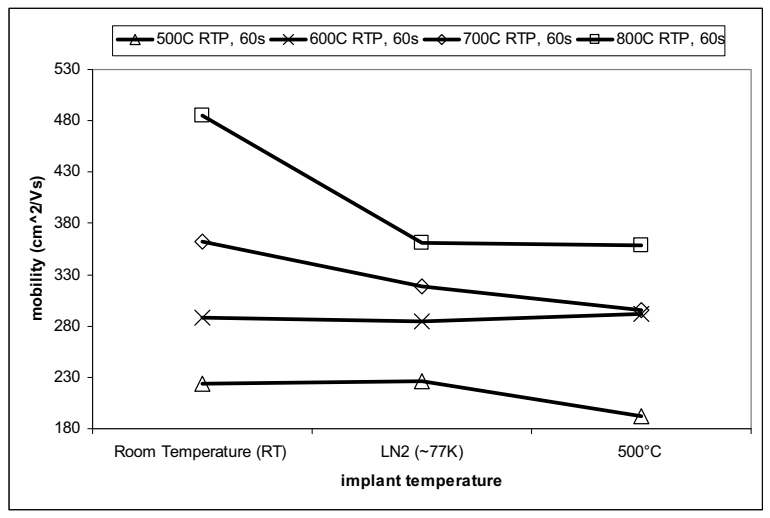

FIGURE 4. Hall mobility after $500,600,700$ and $800^{\circ} \mathrm{C}$ annealing for different phosphorus implantation temperatures.

As shown in figure 4, Hall mobility increases as the annealing temperature increases for all the implants. The values of electron mobility increase maybe due to the reduction of implantation damage as the anneal temperature increase.

To examine the influence of time, isothermal anneals were carried out at $800^{\circ} \mathrm{C}$ for times between 3 and 120 seconds. $800^{\circ} \mathrm{C}$ was chosen since this is the temperature where the sheet carrier concentration of phosphorus is the highest for $\mathrm{LN}_{2} \& 500^{\circ} \mathrm{C}$ implants. The results for isothermal anneal at $800^{\circ} \mathrm{C}$ is shown in Figure 5.

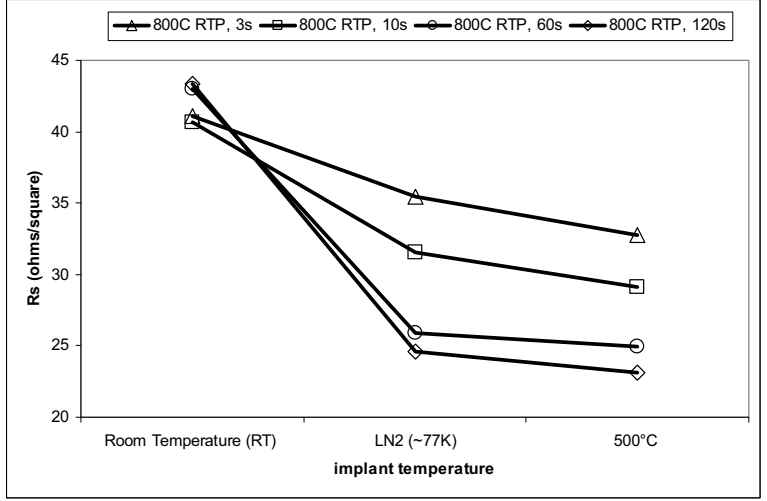

FIGURE 5. Sheet resistance after $800^{\circ} \mathrm{C}$ annealing for different phosphorus implantation temperatures.

As expected, the sheet resistances for $\mathrm{LN}_{2} \& 500^{\circ} \mathrm{C}$ implants are observed to decrease as the time increase due to the diffusion of localised phosphorus into substitutional sites. However, time does not affect the sheet resistance for the sample implanted at RT because of the thermally stable bond of phosphorus with vacancies, which prevent the phosphorus from diffusing into the substitutional site.

\section{CONCLUSION}

We have studied the germanium damage and phosphorus activation as a function of implant temperature. Implantation induced amorphisation can be avoided by implantation at high temperature and complete amorphisation can be achieved by implantation at low temperature. Phosphorus activation was found to be improved at high and low temperature implant compared to room temperature implant. However, secondary ion mass spectroscopy (SIMS) needs to be carried out in the future, in order to investigate the junction depth profile.

\section{ACKNOWLEDGMENTS}

M. Razali would like to acknowledge the support of the Malaysian Ministry of Higher Education (MOHE) for supporting his $\mathrm{PhD}$ studentship. The authors would like to thank the Surrey Ion Beam Centre for their funding support to attend the IIT 2012 conference.

\section{REFERENCES}

1. A. Satta, et al., Appl. Phys. Lett., 87, 172109, 2005

2. The International Technology Roadmap for Semiconductors, 2011

3. M. Caymax, et al., in 2009 Ieee International Electron Devices Meeting, ed New York: Ieee, 2009, pp. 428-431 
4. J. Kim, et al., Electrochemical and Solid State Letters, vol. 13, pp. II12-II15, 2010

5. H. Bracht, et al., Physical Review Letters, vol. 103, Dec 2009

6. P. Tsouroutas, et al., Materials Science in Semiconductor Processing, vol. 9, pp. 644-649, Aug-Oct 2006.

7. N.P. Barradas and C. Jeynes, Nuclear Instruments and Methods in Physics Research B 266 (2008) 1875-1879

8. H. Poon, et al., Journal of the Electrochemical Society, vol. 152, pp. G895-G899, 2005.

9. E. Simoen, et al., Materials Science in Semiconductor Processing, vol. 9, pp. 634-639, Aug-Oct 2006 